\title{
Geldanamycin and herbimycin A induce apoptotic killing of B chronic lymphocytic leukemia cells and augment the cells' sensitivity to cytotoxic drugs
}

Dylan T. Jones, Elena Addison, Janet M. North, Mark W. Lowdell, A. Victor Hoffbrand, Atul B. Mehta, Kanagasabai Ganeshaguru, Najeem I. Folarin, and R. Gitendra Wickremasinghe

We studied the actions of geldanamycin (GA) and herbimycin A (HMA), inhibitors of the chaperone proteins Hsp90 and GRP94, on B chronic lymphocytic leukemia (CLL) cells in vitro. Both drugs induced apoptosis of the majority of CLL isolates studied. Whereas exposure to 4-hour pulses of 30 to 100 nM GA killed normal B lymphocytes and CLL cells with similar dose responses, $T$ lymphocytes from healthy donors as well as those present in the CLL isolates were relatively resistant. GA, but not HMA, showed a modest cytoprotective effect toward CD34+ hematopoietic progenitors from normal bone marrow. The ability of bone marrow progenitors to form hematopoietic colonies was unaffected by pulse exposures to GA. Both GA and HMA synergized with chlorambucil and fludarabine in killing a subset of CLL isolates. GA- and HMA-induced apoptosis was preceded by the up-regulation of the stress-responsive chaperones Hsp70 and BiP. Both ansamycins also resulted in downregulation of Akt protein kinase, a modula- tor of cell survival. The relative resistance of $\mathrm{T}$ lymphocytes and of $\mathrm{CD} 34^{+}$bone marrow progenitors to GA coupled with its ability to induce apoptosis following brief exposures and to synergize with cytotoxic drugs warrant further investigation of ansamycins as potential therapeutic agents in CLL. (Blood. 2004;103:1855-1861)

๑) 2004 by The American Society of Hematology

\section{Introduction}

B chronic lymphocytic leukemia (CLL) is characterized by the clonal expansion of $\mathrm{CD} 5^{+} \mathrm{CD} 19^{+} \mathrm{B}$-lymphoid cells. Although CLL cells proliferate slowly, defective apoptosis results in progressive accumulation of the malignant clone. ${ }^{1-3}$ The clinical course of CLL is highly variable. Although a proportion of patients survive for extended periods without the need for clinical intervention, others undergo rapid disease progression and require aggressive treatment. Recent studies have established that a subset of patients with CLL with unmutated immunoglobulin heavy chain variable $\left(\operatorname{IgV}_{\mathrm{H}}\right)$ genes have an inferior clinical outcome compared to the subset with mutated $\mathrm{IgV}_{\mathrm{H}}$ genes. ${ }^{4,5}$ Furthermore, expression of the protein tyrosine kinase ZAP-70 correlates well with an unmutated $\operatorname{IgV}_{\mathrm{H}}$ status, providing an accessible alternative criterion for the management of patients with CLL. ${ }^{6-8}$ There is an urgent need to develop novel protocols for the treatment patients with a poor prognosis identified by $\operatorname{IgV}_{\mathrm{H}}$ mutation analysis or ZAP-70 expression.

For many years, the nitrogen mustard chlorambucil has been the drug of choice in CLL. More recently, the nucleoside analog fludarabine has proved useful, especially for the treatment of patients who fail to respond to chlorambucil. ${ }^{9}$ Although high remission rates have been achieved using this drug, ${ }^{10}$ myelosuppression has proved to be a critical dose-limiting factor. ${ }^{11}$ Fludarabine is also highly toxic to $\mathrm{T}$ lymphocytes and results in prolonged depression of $\mathrm{CD}^{+}{ }^{+} \mathrm{T}$ cells, increasing the risk of opportunistic infections. ${ }^{11,12}$ Therefore, there has been considerable interest in identifying novel drugs that induce CLL apoptosis with greater selectivity. ${ }^{13-24}$

Deletion of the p53 tumor suppressor gene, whose protein product is a key mediator of drug-induced apoptosis, predicts a

From the Department of Hematology, Royal Free and University College Medical School, London, United Kingdom.

Submitted May 19, 2003; accepted October 17, 2003. Prepublished online as Blood First Edition Paper, October 23, 2003; DOI 10.1182/blood-2003-05-1603.

Supported by the Leukaemia Research Fund, United Kingdom.

Reprints: R. Gitendra Wickremasinghe, Department of Hematology, Royal poor response to cytotoxic drugs. ${ }^{25,26}$ However, even CLL cells harboring intact p53 genes may be defective in p53-mediated apoptosis, resulting from the inactivation of the ATM protein kinase pathway, ${ }^{27-30}$ which links DNA damage induction to p53 up-regulation. Because of the limitations of existing therapeutic options, ${ }^{9-12,25-30}$ it is important to evaluate drugs that induce apoptosis of CLL cells via actions on novel cellular targets. ${ }^{24}$ Optimal new drugs would display a high degree of selectivity for the malignant cells while sparing hematopoietic progenitors and $\mathrm{T}$ lymphocytes. Further advantageous characteristics include a p53independent mode of action and synergistic actions with conventional cytotoxic drugs.

The ansamycin antibiotics geldanamycin (GA) and herbimycin A (HMA) have attracted interest as potential anticancer agents. ${ }^{31,32}$ These drugs target the adenosine triphosphate (ATP)-binding pocket of the cytosolic chaperone heat shock protein 90 (Hsp90). ${ }^{33}$ Hsp90 ensures maintenance of the correctly folded conformation of a range of client proteins involved in signal transduction, including Akt, Raf-1, Erb B2, and the cyclin-dependent kinases cdk4 and cdk6. Therefore, inhibition of Hsp90 by GA or HMA results in the destabilization of proteins critical for survival or proliferation and the resulting cellular stress often results in cell death or cell cycle arrest. ${ }^{31,32}$ In addition to Hsp90, ansamycins can also target its endoplasmic reticulum (ER)-resident homolog GRP94, ${ }^{34}$ resulting in accumulation of misfolded proteins in this cellular compartment. ${ }^{35}$ The resulting ER stress initiates signaling pathways that modulate transcriptional up-regulation of a second ER chaperone, $\mathrm{BiP}^{34} \mathrm{ER}$ stress can also result in the induction of apoptosis in some cellular contexts. ${ }^{36-38}$
Free and University College Medical School, Rowland Hill St, London NW3 2PF, United Kingdom; e-mail: r.wickremasinghe@rfc.ucl.ac.uk.

The publication costs of this article were defrayed in part by page charge payment. Therefore, and solely to indicate this fact, this article is hereby marked "advertisement" in accordance with 18 U.S.C. section 1734.

(C) 2004 by The American Society of Hematology 
Here we have studied the actions of GA and HMA on CLL cells in vitro. We show that CLL cells are sensitive to brief pulses of GA at low nanomolar concentrations, whereas bone marrow CD34 ${ }^{+}$ stem cells and T cells are substantially more resistant to the drug. Synergistic interactions between GA and cytotoxic drugs are also documented. GA is also shown to induce apoptosis by a p53independent mechanism.

\section{Patients, materials, and methods}

\section{Reagents}

Tissue culture materials were from Invitrogen (Paisley, United Kingdom). Chlorambucil, fludarabine, and 3-4,5-dimethylthiazol-2,5-diphenyl tetrazolium bromide (MTT) were from Sigma (Poole, United Kingdom). HMA and GA were from Calbiochem (Nottingham, United Kingdom). All drugs were dissolved in dimethyl sulfoxide and stored at $-20^{\circ} \mathrm{C}$ in aliquots. Annexin V was from Bender MedSystems (San Bruno, CA).

\section{Patients and cells}

This investigation was approved by the institutional Ethics Committee of the Royal Free Hospital, London, United Kingdom. Patients with CLL were classified into Binet stages A, B, or C by established clinical criteria. ${ }^{39}$ Patients had not received treatment for at least 3 months prior to study. After patients provided informed consent, peripheral blood was collected in heparinized vials. Malignant cells were isolated by sedimentation on Lymphoprep gradients (Matrix Technologies, Wimslow, United Kingdom) as described. ${ }^{40}$ All CLL isolates studied contained less than $5 \% \mathrm{CD}^{+}$cells as determined by fluorescence-activated cell sorting (FACScan) analysis. ${ }^{40}$ Cells were cultured in RPMI 1640 medium supplemented with $100 \mathrm{U} / \mathrm{mL}$ penicillin, $100 \mu \mathrm{g} / \mathrm{mL}$ streptomycin, and $10 \%$ fetal calf serum.

Normal peripheral blood mononuclear cells were isolated on Lymphoprep gradients. Monocytes were depleted by adherence on plastic tissue culture surfaces. ${ }^{40} \mathrm{~B}$ and $\mathrm{T}$ lymphocytes were isolated by negative selection procedures using the appropriate magnetically activated cell sorting (MACS) immunomagnetic cell isolation kits (Miltenyi Biotec, Bergisch Gladbach, Germany) and subsequently cultured in basal medium. B and T cells were more than $95 \%$ pure as judged by FACScan analysis of CD19 and CD2 expression.

$\mathrm{CD}_{4}{ }^{+}$cells were isolated from normal bone marrow using the Direct CD34 Progenitor Cell Isolation Kit (Miltenyi Biotec). More than 90\% of the isolated cells were $\mathrm{CD} 34^{+}$by FACScan analysis and were cultured in basal medium additionally supplemented with $10 \mathrm{ng} / \mathrm{mL}$ interleukin 3 and $40 \mathrm{ng} / \mathrm{mL}$ each of stem cell factor and Flt 3 ligand (Peprotech, London, United Kingdom).

\section{Determination of $\mathrm{IC}_{50}$ and combination index}

Cytotoxicity was assessed by carrying out triplicate assays for the reduction of MTT. ${ }^{41}$ Synergistic drug actions were evaluated by computing the combination index $(\mathrm{CI})$ as described. ${ }^{42}$ Cytotoxic drugs and ansamycins were combined at ratios determined by their approximate inhibitory concentration of $50 \%\left(\mathrm{IC}_{50}\right)$ values toward CLL cells. ${ }^{42}$ The cytotoxic actions of serial 2-fold dilutions of these fixed-ratio combinations as well as the effects of individual drugs were determined. Data were analyzed by constructing median effect plots using CalcuSyn software (Biosoft, Ferguson, $\mathrm{MO}$ ). Values of $\mathrm{IC}_{50}$ and $\mathrm{CI}$ were obtained from these plots. CI values more than 1.1 were considered to indicate antagonistic drug interactions, those between 0.9 and 1.1 were considered to indicate additivity, and those below 0.9 were considered to indicate synergistic interactions. ${ }^{42}$

\section{FACScan analysis of cell killing}

Cells $\left(5 \times 10^{6} / \mathrm{mL}\right)$ were exposed to 4 -hour pulses of HMA or GA, washed, and resuspended in basal medium. Following a further 20-hour incubation, cell death was evaluated by FACScan analysis of annexin V-stained cells as described. ${ }^{43}$ CLL and normal lymphoid populations were simultaneously stained with phycoerythrin-labeled anti-CD19 antibody (Becton Dickinson, Oxford, United Kingdom) to allow separate analysis of the $\mathrm{CD} 19^{+}$(B-cell) and CD19-
(T-cell) populations. Residual monocytes were excluded from analysis by using forward versus side scatter to gate on the lymphoid population.

Agent-specific cell death was computed using a published equation ${ }^{44}$ : agent-specific death $=\%$ annexin-positive cells induced by agent $-\%$ annexin-positive cells in untreated control/100 - \% annexin-positive cells in untreated control.

\section{Culture of bone marrow progenitor cells}

Bone marrow cells were incubated in triplicate in methylcellulosecontaining cultures as described, ${ }^{45}$ using the MethoCult GFH4434 kit (StemCell Technologies, Vancouver, BC, Canada). Granulocyte-macrophage colony-forming units (CFU-GMs) and erythroid burst-forming units (BFU-Es) were scored after 14 days of incubation.

\section{Western blotting}

Proteins were extracted as described. ${ }^{46}$ Protein concentrations were determined using a colorimetric assay (Bio-Rad, Hemel Hempstead, United Kingdom). Twenty-five micrograms protein per lane was loaded onto $4 \%$ to $12 \%$ sodium dodecyl sulfate-polyacrylamide gradient gels (Invitrogen). Following electrophoresis, proteins were transferred onto Hybond enhanced chemiluminescence (ECL) membranes (Amersham International, Little Chalfont, United Kingdom). Membranes were blocked in Trisbuffered saline ( $20 \mathrm{mM}$ Tris [tris(hydroxymethyl)aminomethane]-HCl, $\mathrm{pH}$ $7.6,150 \mathrm{mM} \mathrm{NaCl}, 0.2 \%$ polyoxyethylene sorbitan monolaureate) containing $5 \%(\mathrm{wt} / \mathrm{vol})$ polyvinylpyrrolidone and $2 \%(\mathrm{vol} / \mathrm{vol})$ calf serum and exposed overnight to primary antibodies in the same solution. Membranes were washed 3 times in Tris-buffered saline and exposed to an appropriate horseradish peroxidase-linked secondary antibody (Dako, Glostrup, Denmark) for 3 hours. Following further washing, immunoreactive bands were detected using the ECL system (Amersham International). Band intensities were quantified using the GS-700 Imaging Densitometer and Quantity One Software (Bio-Rad).

Antibodies against the following proteins were used in Western blotting experiments: p116 poly(ADP ribose) polymerase (PARP) and XIAP (Becton Dickinson); p85 PARP (Promega, Southampton, United Kingdom); $\beta$-actin (Sigma); Bcl-2 (Dako); p53 (anti-DO-1 monoclonal), Raf, Mcl-1, Hsp70, and BiP/GRP78 (Santa Cruz Biotechnology, Wembley, United Kingdom); and Akt (Cell Signaling Technologies, Hitchin, United Kingdom).

For analysis of ZAP-70 expression, CLL cells were purified further by removal of T lymphocytes using the B-cell isolation kit (Miltenyi Biotec). Final preparations contained less than $0.5 \% \mathrm{CD} 2^{+}$cells. Western blots were analyzed using a ZAP-70 antibody (Upstate Biotechnology, Lake Placid, $\mathrm{NY}$ ) and normalized with respect to actin.

\section{Polymerase chain reaction}

RNA extraction, cDNA syntheses, and polymerase chain reactions (PCRs) were carried out as described. ${ }^{40}$ Primer sequences were as follows: BiP (annealing temperature $55^{\circ} \mathrm{C}$ ): forward: GTT CTC ACT AAA ATG AAA GAA ACC GCT; reverse: GGA CGG GCT TCA TAG TAG ACC G; actin (annealing temperature $58^{\circ} \mathrm{C}$ ) forward: TGC TAT CCA GGC TGT GCT AT; reverse: GAT GGA GTT GAA GGT AGT TT.

PCR products were fractionated on agarose gels and stained with ethidium bromide. Band intensities were quantified using the Gel Doc 2000 system (Bio-Rad).

\section{Statistical methods}

The significance of the difference between mean $\mathrm{IC}_{50}$ or $\mathrm{CI}$ values between different subsets of patients with CLL was evaluated using Student $t$ test for unpaired samples. Differences between $\mathrm{IC}_{50}$ values for cytotoxic drugs in the absence or presence of ansamycins were compared using the $t$ test for paired samples. 


\section{Results}

\section{GA is selectively toxic toward CLL cells}

We used the annexin V-binding assay ${ }^{43}$ to compare the sensitivities of CLL cells, normal $\mathrm{T}$ and $\mathrm{B}$ lymphocytes, and $\mathrm{CD} 34^{+}$bone marrow hematopoietic progenitor cells to GA and HMA. In this series of experiments, cells were exposed to 4-hour pulses of the drugs, then washed and incubated for a further 24 hours prior to quantitation of agent-specific cell killing. CLL cells and normal B lymphocytes were equally sensitive to GA at all concentrations tested (Figure 1A). However, T lymphocytes from healthy donors were substantially less sensitive than CLL cells. Autologous T cells present in the CLL isolates were less sensitive than CLL cells, but were more sensitive than T cells from healthy donors. The different sensitivities of normal and autologous $\mathrm{T}$ cells may be accounted for by the altered distribution of T-cell subsets in CLL. ${ }^{2}$ GA protected $\mathrm{CD}^{2} 4^{+}$cells from spontaneous apoptosis (Figure 1A).

HMA was also equally toxic toward CLL cells and normal B lymphocytes (Figure 1B). Whereas normal T cells were relatively resistant to HMA, patients' autologous T cells were as sensitive as CLL cells. Normal CD34 ${ }^{+}$hematopoietic progenitors were essentially resistant to $300 \mathrm{nM}$ HMA but were more sensitive at higher concentrations of the drug (Figure 1B). Taken together, these data suggest that GA shows a greater selectivity in killing CLL cells than does HMA.

We confirmed the resistance of hematopoietic progenitors to GA by exposing bone marrow mononuclear cells to 4-hour pulses of 30 or $100 \mathrm{nM}$ of the ansamycin, followed by plating in standard colony-forming assays. The data summarized in Table 1 show that neither the formation of granulocyte-macrophage colonies nor of erythroid bursts was inhibited by exposure to GA.

\section{Sensitivity of CLL isolates to ansamycins is independent of ZAP-70 status}

$\mathrm{IC}_{50}$ values for GA, derived from MTT dye reduction assays, are listed in Table 2, together with clinicopathologic data on individual

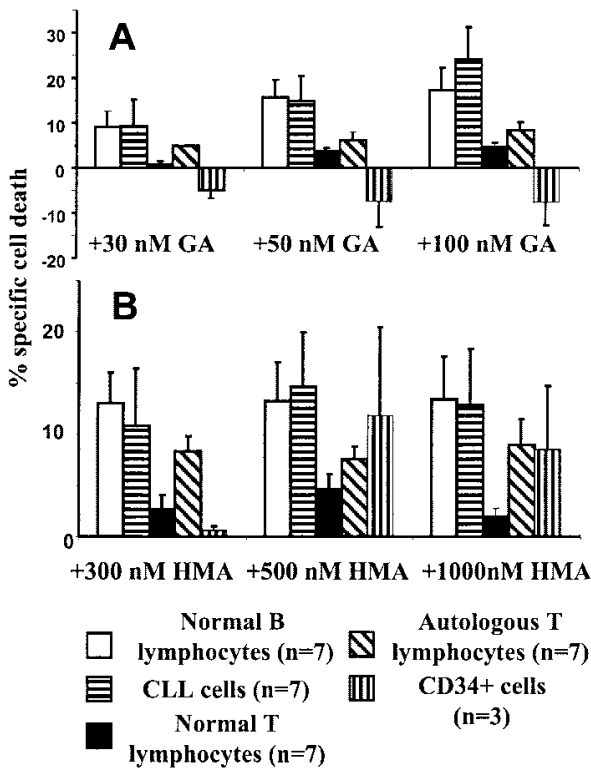

Figure 1. Toxicity of GA and HMA toward lymphocytes and bone marrow progenitors. Cells were incubated at $37^{\circ} \mathrm{C}$ for 4 hours with the indicated concentrations of GA (A) or HMA (B), washed free of the drug, and incubated for a further 24 hours. Specific cell death was quantified by annexin V staining. Error bars indicate SEM.
Table 1. Effect of a GA pulse on colony formation by bone marrow progenitors

\begin{tabular}{lrc}
\hline & +30 nM GA $(\boldsymbol{P})$ & $+\mathbf{1 0 0} \mathbf{~ n M ~ G A ~}(\boldsymbol{P})$ \\
\hline CFU-GM & $96 \pm 14(.72)$ & $112 \pm 15(.64)$ \\
BFU-E & $106 \pm 23(.94)$ & $131 \pm 16(.19)$ \\
Total colonies & $98 \pm 18(.89)$ & $100 \pm 9.5(.03)$
\end{tabular}

Bone marrow mononuclear cells from 3 healthy donors were incubated for 4 hours at $37^{\circ} \mathrm{C}$ with the indicated concentrations of $\mathrm{GA}$, washed free of the drug, and plated for assay of colony formation. Colonies were counted at 14 days. Data are shown as percentages of colonies detected in untreated cultures \pm SEM. $P$ values were determined by the Student $t$ test for paired samples.

patients and their ZAP-70 expression status. $\mathrm{IC}_{50}$ values ranged from 0.01 to $0.68 \mu \mathrm{M}$, with a median value of $0.06 \mu \mathrm{M}$. There was no significant difference $(P=.45)$ between the mean $\mathrm{IC}_{50}$ for the $\mathrm{ZAP}^{-70^{-}}(0.17 \pm 0.08 \mu \mathrm{M} ; \mathrm{n}=10)$ and $\mathrm{ZAP}-70^{+}(0.10 \pm 0.04$ $\mu \mathrm{M} ; \mathrm{n}=11$ ) isolates.

$\mathrm{IC}_{50}$ values for HMA are listed in Table 3. The median $\mathrm{IC}_{50}$ $(0.31 \mu \mathrm{M})$ was 5-fold greater than that for GA. Again, there was no significant difference $(P=.29)$ between the mean $\mathrm{IC}_{50}$ for the $\mathrm{ZAP}-70^{-}(0.48 \pm 0.24 \mu \mathrm{M} ; \mathrm{n}=4)$ and $\mathrm{ZAP}-70^{+}(0.27 \pm 0.09 \mu \mathrm{M}$; $\mathrm{n}=9$ ) isolates.

The sensitivities of CLL isolates toward either GA or HMA also failed to correlate with Binet stage, treatment history, or lymphocyte count (Table 2).

\section{GA up-regulates chaperone protein expression in CLL cells}

We carried out Western blot experiments to determine the molecular consequences of GA treatment of CLL cells. GA induced activation of the apoptotic protease caspase 3 , as evidenced by the cleavage of its substrate PARP to an $85-\mathrm{kDa}$ fragment (Figures 2 and 3). Inhibition of the functions of the cytosolic chaperone Hsp90 and of the ER-resident chaperone GRP94 often result in upregulation of $\mathrm{Hsp} 70^{47}$ and $\mathrm{BiP},{ }^{34}$ respectively. GA-induced upregulation of $\mathrm{Hsp} 70$, but not of $\mathrm{BiP}$, was evident in cells from patient 3 (Figure 2), whereas both chaperones were up-regulated in cells from patient 20 (Figure 3). In a total of 7 isolates studied, simultaneous up-regulation of $\mathrm{BiP}$ and $\mathrm{Hsp} 70$ was seen in 5 isolates and of either BiP or Hsp70 only in one each of the remaining 2 samples (not shown). These data suggest that the induction of a heat shocklike response via inhibition of Hsp70, of an ER stress response via blockade of GRP98, or both, may contribute to killing of CLL cells by GA.

The Akt protein kinase plays a key role in maintaining the survival of CLL cells. ${ }^{46}$ A marked decline in levels of this protein was evident 4 hours after addition of GA to cells from patient 3 and was sustained over the subsequent 20 hours (Figure 2). We failed to detect significant diminutions in expression of the antiapoptotic proteins Bcl-2 and Mcl-1 and of XIAP or of the Raf protein kinase in the same experiment (Figure 2).

A more transient decline in Akt levels was evident at 4 hours when cells from patient 20 were treated with GA (Figure 3). Levels of Mcl-1 and XIAP were decreased following 24 hours of incubation with the ansamycin. Because these events were coincident with the onset of caspase activation, it is not clear whether down-regulation of any of these antiapoptotic proteins may have contributed to cell killing or were merely a consequence of activation of apoptotic proteases. However, in a total of 7 isolates studied, a decline in Akt levels preceding caspase activation was clearly evident in 6 experiments, suggesting that this event may contribute to GA-induced apoptosis induction in the majority of cases. 
Table 2. IC Fo $_{50}$ values for chlorambucil or fludarabine alone or in the presence of GA

\begin{tabular}{|c|c|c|c|c|c|c|c|c|c|}
\hline \multirow{2}{*}{$\begin{array}{l}\text { Patient } \\
\text { no. }\end{array}$} & \multirow{2}{*}{$\begin{array}{l}\text { Sex/age, } \\
y / \text { stage }\end{array}$} & \multirow{2}{*}{$\begin{array}{l}\text { Previous } \\
\text { treatment }\end{array}$} & \multirow{2}{*}{$\begin{array}{c}\text { Lymphocyte count, } \\
\times 10^{9} / \mathrm{L}\end{array}$} & \multirow{2}{*}{$\begin{array}{l}\text { ZAP-70 } \\
\text { status }\end{array}$} & \multicolumn{5}{|c|}{$\mathrm{IC}_{50}, \mu \mathrm{M}$} \\
\hline & & & & & $\overline{G A}$ & Chl & $\mathrm{Chl} / \mathrm{GA}, 1000: 1$ & Flu & Flu/GA, 100:1 \\
\hline 1 & $\mathrm{M} / 72 / \mathrm{A}$ & $\mathrm{Chl}$ & 66.8 & Negative & 0.61 & 24.2 & 23.7 & 3.3 & 2.2 \\
\hline 2 & $\mathrm{M} / 78 / \mathrm{A}$ & None & 54.1 & Negative & 0.17 & 61.8 & $13.7^{\star}$ & 1.2 & $0.3^{*}$ \\
\hline 3 & $\mathrm{M} / 72 / \mathrm{A}$ & $\mathrm{Chl}$ & 66.7 & Positive & 0.08 & 167 & $14.3^{*}$ & 5.4 & $1.7 \dagger$ \\
\hline 4 & $\mathrm{~F} / 75 / \mathrm{B}$ & None & 47.4 & Positive & 0.14 & 68.6 & $16.3^{*}$ & 3.3 & $1.6 \dagger$ \\
\hline 5 & $\mathrm{M} / 72 / \mathrm{C}$ & $\mathrm{Chl} / \mathrm{Flu}$ & 74.9 & Positive & 0.11 & 27.8 & $9.0 \dagger$ & 2.0 & $0.96 \dagger$ \\
\hline 6 & $\mathrm{M} / 76 / \mathrm{C}$ & None & 25.9 & Positive & 0.50 & 50.9 & 42.3 & 7.5 & 4.8 \\
\hline 7 & $\mathrm{M} / 73 / \mathrm{B}$ & $\mathrm{Chl}$ & 30.8 & Positive & 0.03 & 8.8 & 10.4 & 0.76 & $0.22 \dagger$ \\
\hline 8 & $\mathrm{M} / 75 / \mathrm{A}$ & None & 23.6 & Negative & 0.09 & 60.5 & $23.3 \dagger$ & 1.2 & 1.2 \\
\hline 9 & $\mathrm{M} / 57 / \mathrm{B}$ & None & 34.0 & Negative & 0.01 & 20.2 & $7.1 \dagger$ & 0.38 & $0.11 \dagger$ \\
\hline 10 & $\mathrm{M} / 56 / \mathrm{B}$ & None & 10.9 & Positive & 0.02 & 13.2 & $5.7 \dagger$ & 2.6 & $0.77 \dagger$ \\
\hline 11 & $\mathrm{M} / 49 / \mathrm{A}$ & None & 24.4 & Positive & 0.06 & 13.3 & $6.5 \dagger$ & 1.1 & 0.75 \\
\hline 12 & $\mathrm{M} / 82 / \mathrm{C}$ & $\mathrm{Chl}$ & 81.1 & Positive & 0.07 & 10.7 & 6.1 & 0.68 & 0.55 \\
\hline 13 & $\mathrm{M} / 83 / \mathrm{A}$ & None & 43.9 & Positive & 0.01 & 5.3 & 3.6 & 0.77 & 0.37 \\
\hline 14 & $\mathrm{~F} / 63 / \mathrm{C}$ & $\mathrm{Chl}$ & 10.1 & Negative & 0.68 & 22.6 & 21.2 & ND & ND \\
\hline 15 & $\mathrm{M} / 66 / \mathrm{C}$ & None & 20.2 & Negative & 0.06 & 20.3 & $10.1 \dagger$ & 0.70 & $0.25 \dagger$ \\
\hline 16 & $\mathrm{M} / 80 / \mathrm{B}$ & None & 45.9 & Negative & 0.03 & 21.8 & $7.6 \dagger$ & 0.45 & $0.20 \dagger$ \\
\hline 17 & $\mathrm{M} / 62 / \mathrm{B}$ & $\mathrm{Chl}$ & 41.2 & Negative & 0.01 & 18.3 & $6.9 \dagger$ & 0.38 & 0.47 \\
\hline 18 & $\mathrm{~F} / 63 / \mathrm{C}$ & $\mathrm{Chl}$ & 108 & Positive & 0.07 & 76.4 & $10.6^{*}$ & 0.87 & 1.2 \\
\hline 19 & $\mathrm{~F} / 69 / \mathrm{C}$ & $\mathrm{Chl}$ & 63.0 & Negative & 0.03 & 44.4 & $8.9^{*}$ & 0.81 & 0.98 \\
\hline 20 & $\mathrm{~F} / 78 / \mathrm{A}$ & None & 25.5 & Positive & 0.04 & 18 & $7.7^{\star}$ & 0.19 & 0.18 \\
\hline 21 & $\mathrm{M} / 70 / \mathrm{A}$ & None & 10.6 & Negative & 0.01 & 7.1 & 5.9 & ND & ND \\
\hline
\end{tabular}

Chl indicates chlorambucil; Flu, fludarabine; and ND, not done.

*Isolates whose $\mathrm{IC}_{50}$ was decreased by more than $75 \%$ in the presence of $\mathrm{GA}$.

tIsolates whose $\mathrm{IC}_{50}$ was decreased by more than $50 \%$ in the presence of $\mathrm{GA}$.

The induction of $\mathrm{BiP}$ in response to induction of ER stress is regulated at the transcriptional level. ${ }^{36}$ We used semiquantitative reverse transcriptase-PCR to show that $\mathrm{BiP}$ transcripts were induced 2- to 3-fold relative to actin transcripts in CLL cells treated for 8 hours with $100 \mathrm{nM} \mathrm{GA}$ (Figure 4). The induction of BiP transcripts by GA was confirmed in 2 additional experiments (not shown).

Treatment of cells from patient 16 with GA or HMA also resulted in the early decline in Akt levels and simultaneous up-regulation of Hsp70 and of BiP (not shown), suggesting similar mechanisms of death induction by both the ansamycins studied here.

\section{GA and HMA synergize with cytotoxic drugs in killing CLL cells}

$\mathrm{IC}_{50}$ values for chlorambucil alone or in the presence of GA at a 1000:1 molar ratio are presented in Table 2. GA decreased the $\mathrm{IC}_{50}$

Table 3. IC $\mathrm{C}_{50}$ values for chlorambucil or fludarabine alone or in the presence of HMA

\begin{tabular}{clcclc}
\hline $\begin{array}{c}\text { Patient } \\
\text { no. }\end{array}$ & HMA & Chl & Chl/HMA, 100:1 & Flu & Flu/HMA, 10:1 \\
\cline { 2 - 6 } & 1.2 & 24.2 & 23 & 3.3 & 4 \\
\hline 1 & 0.45 & 61.8 & $12.6^{*}$ & 1.2 & 0.77 \\
\hline 2 & 0.86 & 167 & $8.9^{*}$ & 5.4 & 1.3 \\
3 & 0.46 & 68.6 & $16.3^{*}$ & 3.3 & 1.6 \\
\hline 4 & 0.31 & 27.8 & 18.4 & 2.0 & 1.1 \\
\hline 5 & 0.65 & 50.9 & 26.6 & 7.5 & $3.3 \dagger$ \\
6 & 0.09 & 8.8 & 5.1 & 0.76 & $0.27 \dagger$ \\
\hline 7 & 0.541 & 60.5 & $20.7 \dagger$ & 1.2 & 1.3 \\
8 & 0.04 & 20.2 & $4.0^{*}$ & 0.38 & 0.29 \\
\hline 9 & 0.14 & 13.2 & 14.6 & 2.6 & 1.9 \\
10 & 0.24 & 13.3 & 10.8 & 1.1 & 0.6 \\
11 & 0.16 & 10.7 & 6.2 & 0.68 & 0.73 \\
12 & 0.06 & 5.3 & 4.1 & 0.77 & 0.34 \\
\hline 13 & & & & & \\
\hline
\end{tabular}

The patient numbers are as described in the first column of Table 2.

*Isolates whose $\mathrm{IC}_{50}$ was decreased by more than $75 \%$ in the presence of $\mathrm{HMA}$. †lsolates whose $\mathrm{IC}_{50}$ was decreased by more than $50 \%$ in the presence of HMA. values for chlorambucil by more than $50 \%$ in $14(67 \%)$ of 21 isolates and by more than $75 \%$ in $6(29 \%)$ of 21 cases. The difference between the mean $\mathrm{IC}_{50}$ for chlorambucil alone (36.2 \pm 8.1 $\mu \mathrm{M})$ or in the presence of GA $(12.4 \pm 2 \mu \mathrm{M})$ was highly significant $(P=.006)$. The ability of GA to have an impact on cell killing by chlorambucil was most clearly evident in isolates that

\begin{tabular}{|c|c|}
\hline & $+100 \mathrm{nM} \mathrm{G}$ \\
\hline Time (h) & $\begin{array}{lllll}8 & 24 & 4 & 8 & 24\end{array}$ \\
\hline p116 PARP & 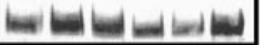 \\
\hline p85 PARP & 패 \\
\hline $85 / p 85+p 116$ & $\begin{array}{lllllll}0 & 0 & 0 & 0 & 0 & .18 \\
\end{array}$ \\
\hline Bcl-2 & 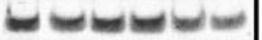 \\
\hline Bcl-2/actin & $\begin{array}{llllll}.98 & .58 & 1.1 & .9 & .74 & .85\end{array}$ \\
\hline Mcl-1 & 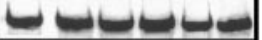 \\
\hline Mcl-1/actin & $\begin{array}{lllll}.5 & .5 & .58 & .52 .45 .47 \\
\end{array}$ \\
\hline XIAP & $n=-m-m$ \\
\hline XIAP/actin & $\begin{array}{llllll}1.1 & .7 & 1.2 & .8 & .74 .8 \\
\end{array}$ \\
\hline Akt & 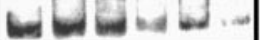 \\
\hline Akt/actin & $\begin{array}{lllllll}1.4 & 1.2 & .8 & .12 & .4 & .17\end{array}$ \\
\hline & 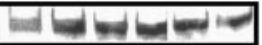 \\
\hline Raf/actin & $\begin{array}{lllllll}43 & .6 & .82 & 1.2 & .4 & .37 \\
\end{array}$ \\
\hline BiP & 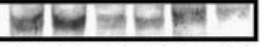 \\
\hline BiP/actin & 2.31 .92 .12 .82 .11 .6 \\
\hline Hsp70 & 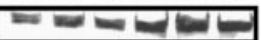 \\
\hline Hsp70/actin & $\begin{array}{llllll}5 & .53 & .84 & 1.1 & 1.2 & 1.8 \\
\end{array}$ \\
\hline Actin & 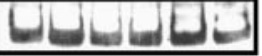 \\
\hline
\end{tabular}

Figure 2. Western blot analysis of GA-treated CLL cells. Cells $\left(10^{7} / \mathrm{mL}\right)$ from CLL patient 3 (Table 2) were incubated in the absence (NA) or presence of $100 \mathrm{nM}$ GA Protein extracts were prepared at the indicated times and analyzed by Western blotting. All bands were quantified by densitometric analysis and their intensities normalized with respect to actin. GA-specific apoptosis at 24 hours, quantified by morphologic criteria, ${ }^{40}$ was $22 \%$. 


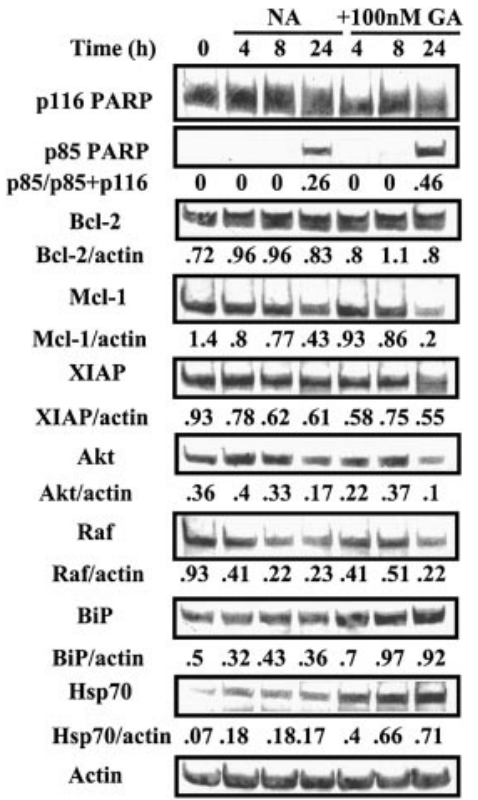

Figure 3. Western blot analysis of GA-treated CLL cells. Cells from CLL patient 20 were incubated in the absence (NA) or presence of $100 \mathrm{nM} \mathrm{GA}$. Protein extracts were prepared at the indicated times and analyzed by Western blotting. GA-specific apoptosis was $26 \%$ at 24 hours.

were relatively resistant to this cytotoxic drug; in isolates with an $\mathrm{IC}_{50}$ more than $35 \mu \mathrm{M}$, this parameter was decreased by more than $50 \%$ in 6 of 7 and by more than $75 \%$ in 5 of 7 cases.

Synergistic interactions between chlorambucil and GA, resulting in CI values below 0.9 , were seen in $12(57 \%)$ of 21 cases at drug concentrations that induced $50 \%$ or $75 \%$ cell killing, increasing to $16(76 \%)$ of 21 cases under conditions of $90 \%$ killing (Figure $5 \mathrm{~A})$. At the $50 \%$ level of killing, 4 of 21 cases gave $\mathrm{CI}$ values more than 1.1, indicative of antagonistic interactions between the 2 drugs. Of these 4 cases, one showed an $\mathrm{IC}_{50}$ for chlorambucil alone of $20.2 \mu \mathrm{M}$ and the remaining 3 of less than $10 \mu \mathrm{M}$, again suggesting that synergistic interactions between the drugs were more pronounced in CLL isolates that were relatively resistant to chlorambucil alone.

GA decreased the $\mathrm{IC}_{50}$ values for fludarabine by more than $50 \%$ in $9(47 \%)$ of 19 isolates and by more than $75 \%$ in only $1(5 \%)$ of 19 cases (Table 2). The difference between the mean $\mathrm{IC}_{50}$ for fludarabine alone $(1.8 \pm 0.4 \mu \mathrm{M})$ or in the presence of GA $(1.0 \pm 0.3 \mu \mathrm{M})$ was not statistically significant $(P=.14 ; \mathrm{n}=19)$. Nevertheless, analysis of CI values showed that clear synergistic interactions between fludarabine and GA were evident in $11(58 \%)$ of 19 isolates at drug concentrations inducing $50 \%$ cell killing, increasing to $16(84 \%)$ of 19 and 17 (89\%) of 19, respectively, under conditions where $75 \%$ and $90 \%$ cell killing were achieved (Figure 5B).

Combinations of HMA with either chlorambucil or fludarabine also resulted in reductions of the $\mathrm{IC}_{50}$ for each cytotoxic drug (Table 3) and in evidence of synergistic interaction (Figure 5C-D), albeit in a smaller proportion of isolates than in the case of GA. CI values pertaining to these combinations suggested that synergistic interactions became more pronounced at drug concentrations that resulted in higher levels of cell killing (Figure 5C-D). However, when data for CLL isolates 1 to 13 were compared, the degree of synergy observed using combinations of chlorambucil or fludarabine with HMA was significantly less than that observed when either cytotoxic drug was combined with GA. For example, at drug concentrations that resulted in $90 \%$ cell killing, the mean CI for chlorambucil plus GA $(0.5 \pm 0.11)$ was significantly lower $(P=.05)$ than the mean CI for chlorambucil plus HMA $(0.8 \pm 0.14)$. Likewise, combination of fludarabine with GA resulted in a mean CI of $0.33 \pm 0.03$, whereas fludarabine plus HMA gave a higher mean value of $0.74 \pm 0.16(P=.02)$.

We observed no statistically significant differences in the $\mathrm{IC}_{50}$ values for chlorambucil or fludarabine alone, or in the CI values pertaining to interactions of either of these drugs with GA, when CLL patients were stratified according to ZAP-70 status or treatment history (not shown).

\section{Cell killing by GA and HMA is not dependent on p53 elevation}

Induction of apoptosis by chlorambucil was associated with the progressive up-regulation of p53, which was maximal at 24 hours of incubation (Figure 6). However, whereas GA alone induced PARP cleavage at 24 hours, this was not preceded by p53 elevation. Apoptosis induction by HMA was also independent of p53 stabilization (not shown). However, treatment with GA and chlorambucil resulted in a substantially earlier peak of p53 elevation (Figure 6). It is therefore plausible that facilitation of p53 induction following DNA damage induction by chlorambucil may account in part for the ability of GA to synergize with chlorambucil in inducing the apoptotic killing of CLL cells.

\section{Discussion}

The results here show for the first time that the ansamycin antibiotics GA and HMA induce apoptotic killing of CLL cells in vitro. The $\mathrm{IC}_{50}$ for the killing of the majority of CLL isolates by GA was below $0.1 \mu \mathrm{M}$, in contrast to the much higher concentrations (approximately $5 \mu \mathrm{M}$ ) required for apoptosis induction of bcr-ablexpressing leukemia cell lines. ${ }^{47}$

GA showed greater selectivity against CLL cells than did HMA. Whereas nonmalignant B lymphocytes were as sensitive as CLL cells to GA, both normal T lymphocytes and T cells present in CLL cell isolates were significantly less sensitive. Several recent studies have identified drugs that show selectivity toward CLL cells compared to normal $\mathrm{T}$ cells. ${ }^{13-23}$ However, the actions of these agents on bone marrow progenitor cells was not investigated. Importantly, we have shown here that GA did not induce apoptosis of $\mathrm{CD}_{3} 4^{+}$progenitor cells from normal bone marrow and may even confer a modest cytoprotective effect.

GA treatment of CLL cells resulted in the up-regulation of Hsp70 and BiP, consistent with the interpretation that the actions of

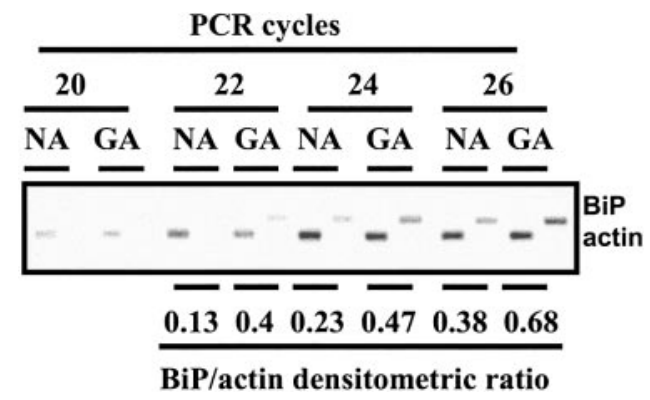

Figure 4. Induction of BiP transcripts by GA. CLL cells were incubated for 8 hours in the absence (NA) or presence (GA) of 100 nM GA. RNA was prepared and analyzed by reverse transcriptase-PCR for actin and BiP transcripts. Following amplification for the indicated cycles, products were fractionated on an agarose gel, stained with ethidium bromide, and visualized using a UV transilluminator. 
A

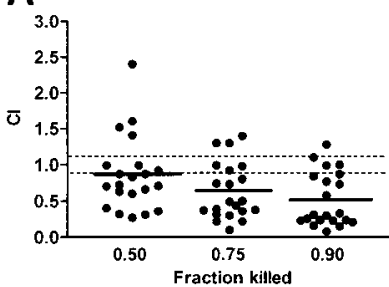

B

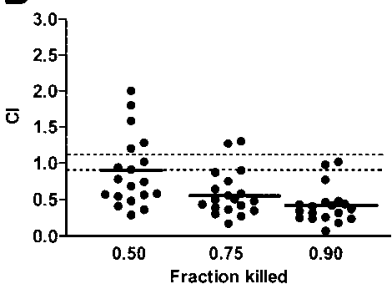

C

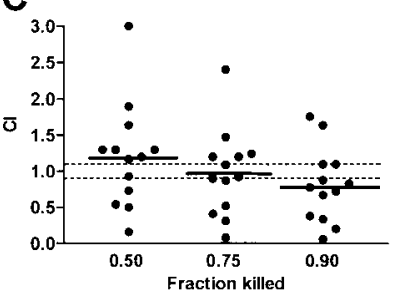

D

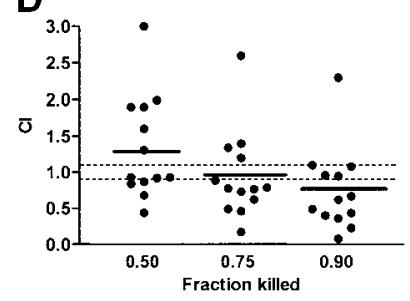

Figure 5. Cl values for combinations of ansamycin antibiotics and cytotoxic drugs. Cl values for the drug combinations shown were computed under conditions where $50 \%, 75 \%$, or $90 \%$ cell killing was achieved. Median $\mathrm{Cl}$ values are shown by solid bars. The dotted lines identify $\mathrm{Cl}$ values between 0.9 and 1.1 , which were considered to indicate additive drug interactions. Values above 1.1 indicate antagonism, whereas values below 0.9 suggest synergy. (A) Chlorambucil/GA (1000:1). (B) Fludarabine/GA (100:1). (C) Chlorambucil/HMA (100:1). (D) Fludarabine/HMA (10:1).

this ansamycin on CLL cells are primarily the consequence of its ability to inhibit the chaperone functions of Hsp90 or GRP94 or both. Cellular levels of the Akt protein kinase were rapidly decreased in the majority of CLL isolates following treatment with GA. Maintenance of Akt in a correctly folded state is highly dependent on Hsp90, ${ }^{31}$ suggesting that down-regulation of this protein, a key mediator of the survival of CLL cells, ${ }^{46}$ may contribute significantly to the mechanism of ansamycin-induced killing. However, it is possible that down-regulation of other client proteins of Hsp90 or GRP94 may also contribute to apoptosis induction.

Paradoxically, inhibition of chaperone proteins may in some instances block apoptosis induction. Hsp70 inhibits cell death by blocking recruitment of procaspase 9 to the Apaf-1 apoptosome, ${ }^{48}$ whereas BiP may inhibit caspase activation directly. ${ }^{49}$ Therefore, inhibition of Hsp90 and GRP94 by GA and the resulting upregulation of $\mathrm{Hsp} 70$ and $\mathrm{BiP}$, respectively, may, in some cellular contexts, override the proapoptotic consequences of chaperone inhibition discussed. It is plausible that the ability of GA to protect CD $34^{+}$bone marrow progenitors from spontaneous apoptosis in culture may be mediated by this mechanism. However, the low numbers of progenitor cells available for study precluded the direct analysis of Hsp70 and BiP induction by GA. It is also possible that antiapoptotic actions of stress-induced chaperones may contribute to the antagonistic interactions between ansamycins and cytotoxic drugs observed in a minority of CLL isolates.

Both GA and HMA synergized with chlorambucil and fludarabine in inducing the killing of a significant proportion of CLL isolates. However, higher degrees of synergy were observed using GA than with HMA. The CI value for each of the pair-wise drug interactions decreased, indicating increasing synergy, as the percentage of cell killing increased. Therefore, ansamycins may be of value in decreasing the doses of cytotoxic drugs required to obtain high levels of killing of the malignant cells. For example, whereas $514 \mu \mathrm{M}$ chlorambucil was required to achieve $90 \%$ killing of the cells from patient 3 , the same level of death was obtained with 40 $\mu \mathrm{M}$ chlorambucil when combined with $0.04 \mu \mathrm{M}$ GA, giving a dose

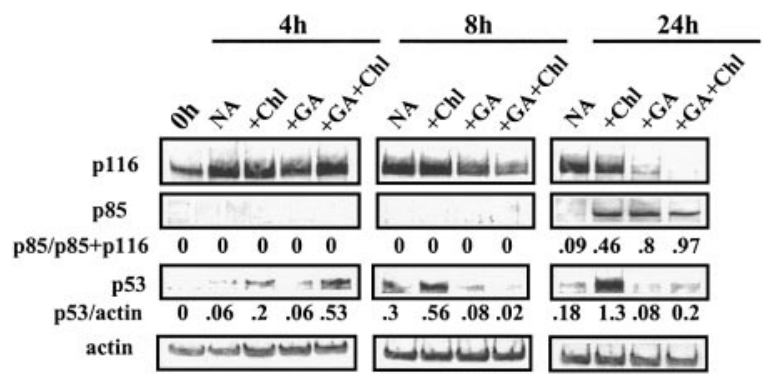

Figure 6. Western blot analysis of CLL cells treated with chlorambucil and GA Cells were incubated with $40 \mu \mathrm{M}$ chlorambucil (Chl), $100 \mathrm{nM} \mathrm{GA}$, or a combination of the 2 drugs. Cells were lysed at the indicated times and analyzed by Western blotting. reduction index ${ }^{42}$ of 12.8 . Therefore, coadministration of ansamycins may allow substantial reductions in the doses of the cytotoxic drugs required to achieve substantial cell killing in vivo. Significantly, the potential for reduction of doses of cytotoxic drugs were most evident in patients whose malignant cells were relatively resistant to the latter agents.

Neither GA nor HMA resulted in elevation of p53, suggesting that CLL cell killing by these agents was not dependent on this pathway. However, we observed that coincubation with GA substantially accelerated the up-regulation of p53 by chlorambucil. It is therefore possible that facilitation of chlorambucil-induced p53 up-regulation by GA may contribute to the observed synergy between these drugs.

Although ansamycins have recently attracted considerable interest as potential anticancer agents, hepatotoxicity is often the dose-limiting factor in their clinical application. However, weekly administration of high-dose ansamycins is better tolerated than chronic exposure to lower doses. ${ }^{31}$ We have shown here that GA pulses at low nanomolar concentrations and as short as 4 hours in duration were sufficient to induce substantial apoptosis of CLL cells. It is therefore plausible that suitable treatment schedules may be devised that exploit the selectivity and potency of GA while minimizing its toxic side effects.

Toxic actions of ansamycins unrelated to their ability to inhibit chaperone proteins may be conferred by their quinone moieties..$^{50}$ Therefore, efforts are underway to exploit ansamycins as guide compounds for the synthesis of novel cancer therapeutic agents showing lower collateral toxicity. A derivative of the compound PU3, which lacks the quinone moiety, has recently been synthesized. This drug inhibits chaperone proteins at submicromolar concentrations, selectively depletes their client proteins, and is freely soluble. ${ }^{51}$ Novel drugs that combine selectivity for chaperone proteins with reduced toxic side effects compared to ansamycins may therefore be of value in future CLL therapy.

In conclusion, the studies reported here identify ansamycins as potential therapeutic agents that induce apoptosis of CLL cells in both $\mathrm{ZAP}^{+}$and $\mathrm{ZAP}^{-}$subtypes of the disease. The relative resistance of $\mathrm{T}$ lymphocytes and of $\mathrm{CD}_{3} 4^{+}$bone marrow progenitors to GA, the ability of this ansamycin to induce p53-independent apoptosis following brief exposures, and its ability to synergize with conventional cytotoxic drugs suggest that further evaluation of GA and of novel inhibitors of chaperone proteins may result in their therapeutic application in the treatment of CLL.

\section{Acknowledgments}

We thank Dan Rowe for BiP primer sequences and Robert Anderson for a gift of cytokines. 


\section{References}

1. Kipps TJ. Chronic lymphocytic leukaemia. Curr Opin Hematol. 1998;5:244-253.

2. Caligaris-Cappio F, Hamblin TJ. B-cell chronic lymphocytic leukaemia: a bird of a different feather. J Clin Oncol. 1999;17:399-408.

3. Kipps TJ. Chronic lymphocytic leukaemia. Curr Opin Hematol. 2000;7:223-234.

4. Hamblin TJ, Davis Z, Gardiner A, Oscier DG Stevenson FK. Unmutated Ig $\mathrm{V}_{\mathrm{H}}$ genes are asso ciated with a more aggressive form of chronic lymphocytic leukemia. Blood. 1999;94:18481854

5. Damle RN, Wasil T, Fais F, et al. Ig V gene mutation status and CD38 expression as novel prognostic indicators in chronic lymphocytic leukemia. Blood. 1999;94:1840-1847.

6. Chen L, Widhopf G, Huynh L, et al. Expression of ZAP-70 is associated with increased B cell receptor signal in chronic lymphocytic leukaemia. Blood. 2002;100:4609-4614.

7. Wiestner A, Rosenwald A, Barry TS, et al. ZAP-70 expression identifies a chronic lymphocytic leukaemia subtype with unmutated immunoglobulin genes, inferior clinical outcome, and distinct gene expression profile. Blood. 2003;101: 4944-4951.

8. Crespo M, Bosch F, Villamor N, et al. ZAP-70 expression as a surrogate for immunoglobulin-variable region mutations in chronic lymphocytic leukaemia. N Engl J Med. 2003;348:1764-1775.

9. Robak T, Kasznicki M. Alkylating agents and nucleoside analogues in the treatment of B-cell chronic lymphocytic leukaemia. Leukemia. 2002; 16:1015-1027.

10. Keating MJ, O'Brien S, Lerner S, et al. Long-term follow up of patients with chronic lymphocytic leukaemia (CLL) receiving fludarabine regimes as initial therapy. Blood. 1998;92:1165-1171.

11. Rai KR, Peterson BL, Appelbaum FR, et al. Fludarabine compared with chlorambucil as primary therapy for chronic lymphocytic leukaemia. N Engl J Med. 2000;343:1750-1757.

12. Anaissie EJ, Kontoyiannis DP, O'Brien S, et al. Infection in patients with chronic lymphocytic leukaemia treated with fludarabine. Ann Intern Med. 1998;129:559-566.

13. Kitada S, Zapata JM, Andreeff M, Reed JC. Protein kinase inhibitors flavopiridol and 7-hydroxystaurosporine down-regulate antiapoptosis proteins in B-cell chronic lymphocytic leukaemia. Blood. 2000;96:393-397.

14. Chandra J, Niemer I, Gilbreath J, et al. Proteasome inhibitors induce apoptosis in glucocorticoid-resistant chronic lymphocytic leukemic lymphocytes. Blood. 1998;92:4220-4229.

15. Masdehors P, Merle-Beral H, Maloum K, Omura $\mathrm{S}$, Magdelenat $\mathrm{H}$, Delic J. Deregulation of the ubiquitin system and $\mathrm{p} 53$ proteolysis modify the apoptotic response in B-CLL lymphocytes. Blood. 2000;96:269-274.

16. Pepper C, Thomas A, Hoy T, Milligan D, Bentley P. Fegan C. The vitamin D3 analog EB1089 induces apoptosis via a p53-independent mechanism involving p38 MAP kinase and suppression of ERK activity in B-cell chronic lymphocytic leukaemia cells in vitro. Blood. 2003;101:2454-2460.

17. Pederson IM, Kitada S, Schimmer A, et al. The triterpenoid CDDO induces apoptosis in refractory CLL B cells. Blood. 2002;100:2965-2972.

18. Moon EY, Lerner A. PDE4 inhibitors activate a mitochondrial apoptotic pathway in chronic lymphocytic leukaemia cells that is regulated by pro tein phosphatase 2A. Blood. 2003;101:4122 4130.
19. Philippousis F, Arguin C, Mateo V, Steff A-M Hugo P. Monoglycerides induce apoptosis in human leukemic cells while sparing normal peripheral blood mononuclear cells. Blood. 2003;101: 292-294

20. Sarfati M, Mateo V, Baudet S, et al. Sildenafil and vardenafil, types 5 and 6 phosphodiesterase inhibitors, induce caspase-dependent apoptosis of B-chronic lymphocytic leukaemia cells. Blood. 2003:101:265-269.

21. Byrd JC, Lucas DM, Mone A, Kitner JB, Drabick JJ, Grever MR. KRN5500: a novel therapeutic agent with in vitro activity against human B-cell chronic lymphocytic leukaemia cells mediates cytotoxicity via the intrinsic pathway of apoptosis. Blood. 2003;101:4547-4550.

22. Anether G, Tinhofer I, Senfter M, Greil R. Tetrocarcin-A-induced ER stress mediates apoptosis in $\mathrm{B}-\mathrm{CLL}$ cells via a Bcl-2-independent pathway. Blood. 2003;101:4561-4568.

23. Ganeshaguru K, Wickremasinghe RG, Jones DT, et al. Actions of the selective protein kinase $\mathrm{C}$ inhibitor PKC412 on B-chronic lymphocytic leukaemia cells in vitro. Haematologica. 2002;87:167 176.

24. Grever MR. In pursuit of a complete remission: exploring novel therapeutic agents in CLL. Blood. 2003;101:2449.

25. Wattel E, Preudhomme C, Hecquet B, et al. p53 mutations are associated with resistance to chemotherapy and short survival in hematologic malignancies. Blood. 1994;84:3148-3157.

26. Dohner $\mathrm{H}$, Fischer $\mathrm{K}$, Bentz $\mathrm{M}$, et al. p53 gene deletion predicts for poor survival and non-response to therapy with purine analogs in chronic B-cell leukemias. Blood. 1995;85:1580-1589.

27. Bullrich F, Rasio D, Kitada S, et al. ATM mutations in B-cell chronic lymphocytic leukaemia. Cancer Res.1999:59:24-27.

28. Starostik P, Manshouri T, O'Brien S, et al. Deficiency of the ATM protein expression defines an aggressive subgroup of B-cell chronic lymphocytic leukemia. Cancer Res. 1998;58:4552-4557.

29. Pettitt AR, Sherrington PD, Stewart G, Cawley JC, Taylor AM, Stankovic T. p53 dysfunction in B-cell chronic lymphocytic leukemia: inactivation of ATM as an alternative to TP53 mutation. Blood. 2001;98:814-822.

30. Lin K, Sherrington PD, Dennis M, Matrai Z, Cawley JC, Pettitt AR. Relationship between p53 dysfunction, $C D 38$ expression and $\lg V_{H}$ mutation in chronic lymphocytic leukemia. Blood. 2002;100: 1404-1409.

31. Neckers L. Hsp90 inhibitors as novel cancer chemotherapeutic agents. Trends Mol Med. 2002;8: S55-S61.

32. Sausville EA. Combining cytotoxics and 17-allylamino 17-demethoxygeldanamycin: sequence and tumor biology matters. Clin Cancer Res. 2001;7:2155-2158.

33. Whitesell L, Mimnaugh EG, De Costa B, Myers CE, Neckers LM. Inhibition of heat shock protein HSP90-pp60v-src heteroprotein complex formation by benzoquinone ansamycins: essential role for stress proteins in oncogenic transformation. Proc Natl Acad Sci U S A. 1994;91:8324-8328.

34. Chavany $C$, Mimnaugh $E$, Miller $P$, et al. p185erbB2 binds to GRP94 in vivo: dissociation of the p185erbB2/GRP94 heterocomplex by benzoquinone ansamycins precedes depletion of p185erbB2. J Biol Chem. 1996;271:4974-4977.

35. Lawson B, Brewer J, Hendershot LM. Geldanamycin, an hsp90/GRP94-binding drug, induces increased transcription of endoplasmic reticulum
(ER) chaperones via the ER stress pathway. J Cell Physiol. 1998;174:170-178.

36. Kaufman RJ. Stress signalling from the lumen of the endoplasmic reticulum: coordination of gene transcriptional and translational controls. Genes Dev. 1999;13:1211-1233.

37. Patil C, Walter P. Intracellular signaling from the endoplasmic reticulum to the nucleus: the unfolded protein response in yeast and mammals. Curr Opin Cell Biol. 2001;13:349-355.

38. Ferri KF, Kroemer G. Organelle-specific initiation of cell death pathways. Nat Cell Biol. 2001;3: E255-E263.

39. Binet JL, Auquier A, Dighiero, G, et al. A new prognostic classification of chronic lymphocytic leukaemia derived from a multivariate survival analysis. Cancer. 1981;48:198-206.

40. Jones DT, Ganeshaguru K, Folarin NI et al. Caspase 8 activation independent of Fas (CD95/ APO-1) signaling may mediate killing of B-chronic lymphocytic leukemia cells by cytotoxic drugs and $\gamma$ radiation. Blood. 2001;98:2800-2807.

41. Twentyman PR, Fox NE, ReesJK. Chemosensitivity testing of fresh leukemia cells using the MTT colorimetric assay. Br J Haematol. 1989;71:19 24.

42. Chou TC, Talalay P. Quantitative analysis of dose-effect relationships: the combined effects of multiple drugs or enzyme inhibitors. Adv Enzyme Regul. 1984;22:27-55.

43. Wuchter C, Krappmann D, Cai Z, et al. In vitro susceptibility to TRAIL-induced apoptosis of acute leukaemia cells in the context of TRAIL receptor gene expression and constitutive NFkappa B activity. Leukemia. 2001;15:921-928.

44. Posovszky C, Friesen C, Herr I, Debatin KM. Chemotherapeutic drugs sensitize pre-B ALL cells for CD95- and cytotoxic T lymphocyte-mediated apoptosis. Leukemia. 1999;13:400-409.

45. Sutherland HJ, Eaves AC, Eaves CJ. Quantitative assays for human hematopoietic progenitor cells. In: Gee AP, ed. Bone Marrow Processing and Purging: A Practical Guide. Boca Raton, FL: CRC Press; 1991:155-171

46. Jones DT, Ganeshaguru K, Anderson RJ, et al. Albumin activates the AKT signaling pathway and protects B-chronic lymphocytic leukaemia cells from chlorambucil- and radiation-induced apoptosis. Blood. 2003;101:3174-3180

47. Nimmanapalli R, O'Bryan E, Bhalla K. Geldanamycin and its analogue 17-allylamino-27-demethoxygeldanamycin lowers Bcr-Abl levels and induces apoptosis and differentiation of Bcr-Ablpositive human leukemic blasts. Cancer Res. 2001;61:1799-1804.

48. Beere HM, Wolf BB, Cain K, et al. Heat-shock protein 70 inhibits apoptosis by preventing recruitment of procaspase- 9 to the Apaf- 1 apopto some. Nat Cell Biol.2000;2:469-475.

49. Rao RV, Peel A, Logvinova A, et al. Coupling en doplasmic reticulum stress to the cell death program: role of the ER chaperone GRP78. FEBS Lett. 2002;514:122-128.

50. Kelland LR, Sharp SY, Rogers PM, Myers T, Workman P. DT-diaphorase expression and tumor cell sensitivity to 17 -allylamino 17 -demethoxygeldanamyin, an inhibitor of heat shock protein 90. J Natl Cancer Inst. 1999;91:1940-1949.

51. Chiosis G, Lucas B, Shtil A, Huezzot H, Rosen N. Development of a purine-scaffold novel class of Hsp90 binders that inhibit the proliferation of cancer cells and induce the degradation of Her2 tyrosine kinase. Bioorg Med Chem. 2002;10:3555 3564. 